\title{
Closer to the native state. Critical evaluation of cryo-techniques for Transmission Electron Microscopy: preparation of biological samples
}

\author{
Lukasz Mielanczyk $^{1^{*}}$, Natalia Matysiak ${ }^{1^{*}}$, Marek Michalski ${ }^{1}$, \\ Rafal Buldak $^{2}$, Romuald Wojnicz ${ }^{1}$
}

*These authors contributed equally to this work

${ }^{1}$ Department of Histology and Embryology, Medical University of Silesia in Katowice, Zabrze, Poland

${ }^{2}$ Department of Physiology, Medical University of Silesia in Katowice, Zabrze, Poland

\begin{abstract}
Over the years Transmission Electron Microscopy (TEM) has evolved into a powerful technique for the structural analysis of cells and tissues at various levels of resolution. However, optimal sample preservation is required to achieve results consistent with reality. During the last few decades, conventional preparation methods have provided most of the knowledge about the ultrastructure of organelles, cells and tissues. Nevertheless, some artefacts can be introduced at all stagesofstandard electron microscopy preparation technique. Instead, rapid freezing techniques preserve biological specimens as close as possible to the native state. Our review focuses on different cryo-preparation approaches, starting from vitrification methods dependent on sample size. Afterwards, we discuss Cryo-Electron Microscopy Of VItreous Sections (CEMOVIS) and the main difficulties associated with this technique. Cryo-Focused Ion Beam (cryo-FIB) is described as a potential alternative for CEMOVIS. Another post-processing route for vitrified samples is freeze substitution and embedding in resin for structural analysis or immunolocalization analysis. Cryo-sectioning according to Tokuyasu is a technique dedicated to high efficiency immunogold labelling. Finally, we introduce hybrid techniques, which combine advantages of primary techniques originally dedicated to different approaches. Hybrid approaches permit to perform the study of difficult-to-fix samples and antigens or help optimize the sample preparation protocol for the integrated Laser and Electron Microscopy (iLEM) technique.(Folia Histochemica et Cytobiologica 2014, Vol. 52, No, 1, 1-17)
\end{abstract}

Key words: cryo-TEM; cryo-fixation; cryo-FIB; CEMOVIS; freeze substitution; iLEM; Tokuyasu method; hybrid technique

\begin{abstract}
Abbreviations:
CEMOVIS - Cryo-Electron Microscopy Of VItreous Sections

CLEM - Correlative Light and Electron Microscopy Cryo-EM - Cryo-Electron Microscopy Cryo-ET - Cryo-Electron Tomography Cryo-FIB - Cryo-Focused Ion Beam ET - Electron Tomography
\end{abstract}

Correspondence address: L. Mielanczyk, Department of Histology and Embryology Medical University of Silesia in Katowice Jordana St. 19, 41-808 Zabrze, Poland tel.: +48 3227228 42; fax: +48 3227228 67; e-mail:mieluk@gmail.com; nmatysiak@sum.edu.pl

(C) Polish Society for Histochemistry and Cytochemistry Folia Histochem Cytobiol. 2014 10.5603/FHC.2014.0001
FIB - Focused Ion Beam

FS - Freeze Substitution

HPF - High Pressure Freezing

IEM - Immuno-Electron Microscopy

iLEM - integrated Laser and Electron Microscopy

PF - Plunge Freezing

RHM - ReHydration Method

ROI - Region Of Interest

SEM - Scanning Electron Microscopy

SFM - Section Fixation Method

SPRF - Self-Pressurized Rapid Freezing

TEM - Transmission Electron Microscopy

TRITC - TetramethylRhodamineIsoThioCyanate

TSEM - Transmission Scanning Electron Microscopy

UA - Uranyl Acetate

VFS - Vitrified Frozen Sections 


\section{Introduction}

The introduction of Transmission Electron Microscopy (TEM) nearly 70 years ago in the life science have made it possible to study the structure and function of cells and tissues at new level of resolution. Different TEM techniques permit the study of the architecture of cells and tissues on the scale of micrometers (conventional TEM), cellular organelles and molecular architecture on the scale of nanometers (CEMOVIS, ET, cryo-ET) and single molecular complexes at near atomic resolution (Single Particle Analysis, Electron Crystallography). The resolution range of TEM locates this technique next to X-ray crystallography and Nuclear Magnetic Resonance on the one side and light microscopy on the other. Therefore, TEM gives unique possibilities to fit biochemical and atomic scale models into structure-function relationships of macromolecules and organelles in the cellular context. Ultrastructural resolution is obtained by using a coherent beam of electrons in the TEM column under high vacuum. Therefore electron microscopists have to deal with a few aspects during sample preparation. First of all, water as the most abundant cellular constituent must be removed or kept immobilized since water under vacuum at room temperature evaporates. Secondly, it is not possible to observe an entire cell or tissue because the specimen has to be thin enough to allow the electrons to penetrate it and create an image. Additionally, biological samples are composed of light elements, so the sample should be stained with heavy metals or some computational method can be used to create specimen contrast. Over the years different preparation techniques have been developed in order to obtain results as close as possible to the native state.

The scope of this review covers different specialised preparation techniques dedicated to cells and tissues. Readers may ask, why another review which covers cryo-preparation topics in TEM sample preparation if there are a lot articles about this subject. The aim of our review is to refresh introduced cryo-preparation techniques and describe some new solutions in this field. We would like to particularly focus on the vitreous cryo-sectioning technique, the limitations of this technique and an emerging solution in the form of cryo-Focused Ion Beam thinning. Other important and remarkable techniques from our point of view are hybrid techniques that are mainly dedicated to high resolution immunolocalization of selected antigens and a new Correlative Light and Electron Microscopy (CLEM) solution - the integrated Laser and Electron Microscopy (iLEM).

The review starts with a commonly used specimen preparation technique, vitrification of water and a short description of the state of the art preservation techniques. We focused our attention on cryo-fixation techniques, such as Plunge Freezing (PF), High Pressure Freezing (HPF) and recently introduced Self-Pressurized Rapid Freezing (SPRF). We did not introduce Slam Freezing and Jet Freezing, because HPF has almost completely replaced these methods [1]. Subsequently, we present different basic processing routes after vitrification in case of pure structural research (CEMOVIS or cryo-FIB) or localization of gene products with immunolabelling. Finally, we describe hybrid techniques, which combine different basic approaches into one optimized protocol dedicated to solving specific problems, such as difficult-to-fix material or antigens. Furthermore, a hybrid approach enables to fulfil specific requirements of novel advanced tools for application in biological studies.

\section{Conventional sample preparation}

For a few decades the "conventional electron microscopy technique' has been one of the methods for sample preparation in TEM. Conventional specimen preparation uses chemical fixation at room temperature. During this process, the biological sample is chemically fixed, usually using aldehydes and osmium tetroxide $\left(\mathrm{OsO}_{4}\right)$, and dehydrated with organic solvents prior to infiltration and embedding in resin. Embedded biological materials are ultra-thinly sectioned and post-stained with salts of heavy metals, such as uranyl, and lead to the introduction of contrast inside the sample. Previous reports revealed that chemical fixation, dehydration, heavy metal staining and plastic embedding can introduce various artefacts. Fixation with glutaraldehyde prior to dehydration results in cross-linking causing aggregation of proteins, collapse of highly hydrated glycans and loss of lipids. Heavy metals can cause additional artefacts in the form of precipitation [2-5]. To sum up, artefacts introduced during conventional sample preparation limit the resolution of biological samples to about $2 \mathrm{~nm}$ [6]. Modern transmission electron microscopes with a field emission gun can obtain sub-angstrom resolution, thus the resolution is mainly limited by the properties of the sample [7]. Therefore the improvement of biological sample fixation has become the challenge for many scientists.

\section{Alternatives to the conventional sample preparation}

An alternative to chemical fixation is cryo-fixation, i.e. physical preservation. The aim of this method is to vitrify biological samples via rapid freezing. Vitrifica- 


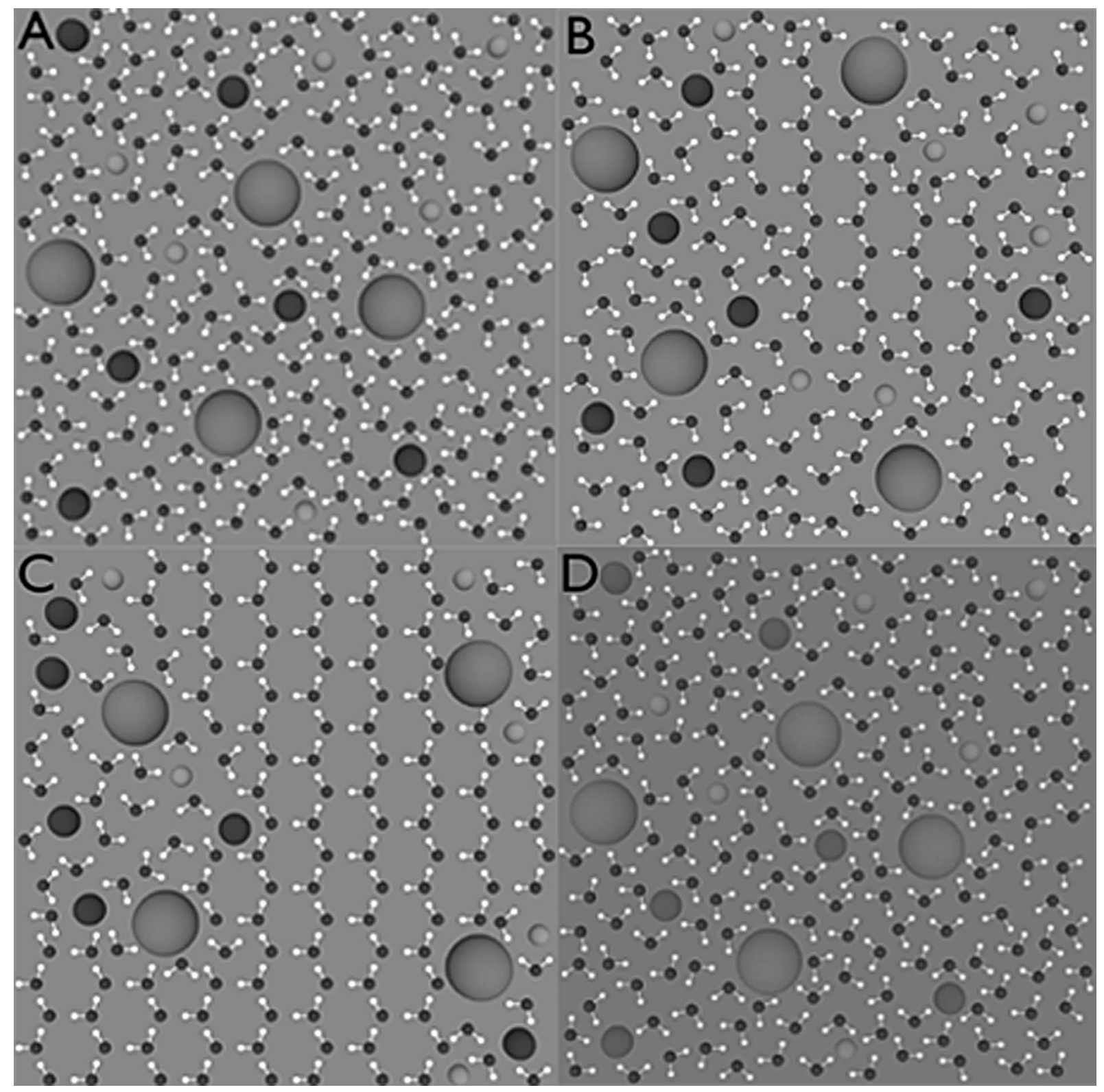

Figure 1.Water state under different cooling rate. A-D. Ice crystal formation in water solutions, known as pattern segregation occurs under lower cooling rate. Water in liquid state with ions (the smallest and medium size) and sugar molecules (the biggest) (A) start to create ice crystals under freezing temperature (B). Created ice crystals devours water molecules which results in separation of solutes from growing ice crystals $(\mathbf{C})$. Water solution under high cooling rate and high pressure transform into amorphous state (D)

tion is a transformation process from the liquid to the amorphous state with the exclusion of the formation of ice crystals within microseconds. Amorphous water can be regarded as a liquid with an extremely high viscosity, thus at the cellular level bioparticles are immobilised in their native state without a change in the cell morphology (Figure 1D). In consequence, cryo-fixation suspends biological processes at a point in time, namely preserving a particular physiological state. Improper vitrification leads to crystalline ice that destroys cellular ultrastructure through a phase segregation process (Figure 1A-C) $[8,9]$.

For a long time it was thought that vitrification of liquid water is impossible for thermodynamical reasons, in spite of the fact that Taylor and Glaeser [10] showed the presence at near atomic resolution of vitrified, fully hydrated catalase crystals. The real breakthrough in the electron microscopy field took place at the beginning of the 1980s. At this time, Bruggeller and Mayer [11] had demonstrated by jet 
freezing and X-ray diffraction that small amounts of water can be vitrified by rapid cooling. A year later Dubochet and McDowall [12] observed that sprayed water drops cooled by immersion in liquid ethane looked structureless. Their surprising finding was confirmed by electron diffraction [13]. Therefore "water is beautiful and its traditional status of foe must be revisited; when treated with suitable care water is electron microscopist's best friend" [14]. This discovery became the basis for the development of cryo-Electron Microscopy (cryo-EM).

Vitrification strongly depends on the cooling rate, cryo-protection and pressure. Thermal properties of water in the biological material are the physical reasons for improper vitrification of thick samples. Under atmospheric conditions only a very thin film (up to $1 \mu \mathrm{m}$ ) of pure water can be vitrified using an extremely high cooling rate [12]. The probability of proper vitrification is higher in the presence of cryoprotectants because water molecules are immobilised. This fact is used in the preparation of biological samples for cryo-sectioning by the Tokuyasu method. Vitrification is obtained due to sample infiltration by sucrose followed by freezing in liquid nitrogen (see Tokuyasu cryo-sectioning method). Although biological samples consist of about $80 \%$ water, cells can be directly vitrified because intracellular components of cells (protein, glycoprotein, lipids, etc.) act as natural cryoprotectants. Thereby the required cooling rate is reduced.

\section{Plunge Freezing}

Plunge Freezing (PF) is the method of choice for a wide range of thickness: from cellular macromolecules and complexes to whole cells up to $10 \mu \mathrm{m}$ thick. This simple method works under atmospheric conditions and enables to obtain high enough cooling rates (equal to at least $104 \mathrm{~K} / \mathrm{s}$ ). Biological samples as small objects are suspended in a thin water film $(100 \mathrm{~nm})$ over holes in the perforated 'support layer' coating EM grids. Larger samples, for example eukaryotic cells, can be grown on EM grids. The prepared sample is plunged into cryogen such as liquid ethane, propane or ethane-propane mixture $[15,16]$. Both liquid ethane and propane in contact with liquid nitrogen solidify, whereas the mixture of these liquid alkanes has a lower freezing point. Thus an ethane-propane mixture remains liquid at $77 \mathrm{~K}$ and therefore this mixture is more convenient to use. Another advantage of the discussed mixture is the fact that it produces less damage to the thin, fragile, holey carbon film on $\mathrm{C}$-grids [17]. After vitrification the sample is either transferred and directly observed at $-180^{\circ} \mathrm{C}$ under the cryo-electron microscope or cryo-thinned. Evaporation is a very important factor during sample preparation because if not controlled it can change the osmotic pressure or surface tension, which can lead to flattening of the sample [13].

\section{High Pressure Freezing}

Samples thicker than $10 \mu \mathrm{m}$ are too thick to ensure proper vitrification without ice crystallisation by $\mathrm{PF}$ and cannot be directly imaged in cryo-EM. The nucleation of ice crystals is temperature and pressure dependent, and this influence is exploited in High Pressure Freezing (HPF) [6]. This method was first introduced by Moor and Riehle in the 1960's [18] but the HPF machine only became commercially available in the 1980's. The volume of water expands during the crystallisation process. According to Le Chatelier and Braun principle, the increase in ice volume can be hindered by application of high pressure which works against expansion and acts as a physical cryo-protectant. High pressure strongly reduces crystal growth and the nucleation rate of ice. As a result, specimens up to $\sim 250 \mu \mathrm{m}$ can be vitreously frozen by application of high pressure (i.e. 2048 bar) and subsequent rapid cooling using liquid nitrogen jets for $\sim 50 \mathrm{~ms}$ [19].

In order to avoid extracellular ice crystallisation, the space around the sample has to be filled with appropriate filler [20]. Usually, the filler is transmission fluid or an extra- or intracellular cryo-protectant solution which does not affect the sample. Another function of filler is to increase the overall cooling rate of the process.

\section{Self-Pressurized Rapid Freezing}

Self-Pressurised Rapid Freezing (SPRF) is a relatively new method, introduced by Leunissen and $\mathrm{Yi}$ in 2007 and further developed by Leunissen and Yi [21]. In this method the material is loaded into standard copper HPF capillaries which are sealed at both ends and plunged into liquid nitrogen, liquid propane or liquid ethane. The essence of this constant volume process is the increase in pressure when the volume of water increases during the freezing process in a sealed capillary [21, 22]. The transformation of water into different crystalline forms of ice at constant volume results in a strong pressure build-up and promotes amorphisation of the sample, which was determined by cryo-EM and electron diffraction [23]. Amorphisation of the sample in a sealed capillary is promoted by the addition of cryo-protective compounds albeit it has been shown that in certain cases the addition of cryo-protectants is unnecessary. 
In comparison with HPF, it is possible to achieve similar pressure and higher rates of heat extraction. In the SPRF method, the concentration of cryo-protectants is lower due to a higher rate of heat transfer through crystalline ice compared to amorphous ice or water. As a result, during the crystallisation process the cooling rate increases, which may minimise cell dehydration [1]. Lower concentrations of cryo-protectants may help to avoid difficulties in sample preparation, such as unfavourable osmotic effects or contrast matching in the images. The depth and quality of vitrified samples through the SPRF method is comparable to samples prepared by HPF, however, during vitrification by SPRF ca. $50 \%$ of the original water mass is changed into crystalline ice, therefore part of the sample is damaged by the formed ice.

\section{Post-processing after vitrification}

Only thin vitrified samples such as purified isolated organelles, macromolecular complexes, viruses, small prokaryotic cells and thinner parts of eukaryotic cells (up to $0,5 \mu \mathrm{m}$ ) can be directly imaged under the cryo-electron microscope [24, 25]. Thicker vitrified samples require a thinning step under cryo-conditions in order to obtain slices thin enough to visualize prior to imaging. Vitreous material can be either cut with a cryo-ultramicrotome by the CEMOVIS procedure or, more recently, thinned with Focused-Ion Beam milling. Alternatively, vitrified samples can be visualized in a standard TEM microscope after a Freeze Substitution process followed by resin embedding or the Tokuyasu technique.

\section{Cryo-Electron Microscopy Of Vitreous Sections}

The first attempts at cryo-sectioning were pioneered by Fernandez-Moran [26] and Bernhard and Leduc [27]. Vitreous sectioning was introduced by Christensen [28] and later developed by McDowall et al. [29]. It was not until 25 years later that the work of Hsieh et al. [30] and Al-Amoudi et al. [31, 32] showed that Cryo-Electron Microscopy Of Vitreous Sections (CEMOVIS) is a reliable method for observing cells and tissues in the native state with molecular resolution. Almost a quarter of century time span was necessary to achieve a technological progress and improvements of specimen preparation protocol [14].

In CEMOVIS all the artefacts of the standard EM preparation technique due to chemical fixation, dehydration, staining and embedding are eliminated $[31,32]$. Biological samples are vitrified by HPF or SPRF usually with $20 \%$ dextran (MW $40 \mathrm{kDa}$ ) to ensure homogeneous vitrification. In the next step of the technique the vitrified sample is transferred in liquid nitrogen to a cryo-chamber in the ultramicrotome where it is mounted with cryo-glue [33]. It is subsequently trimmed and sectioned on the dry knife under adequate temperature (below $-140^{\circ} \mathrm{C}$ ). An increase in temperature leads to devitrification, therefore all the steps with the vitreous material must be performed below this temperature. The obtained sections are placed on carbon coated EM grids, and then transferred to the cryo-EM using a cryo-holder where they are observed at $-180^{\circ} \mathrm{C}$ under low-dose of electron beam conditions or may be stored in liquid nitrogen for long periods of time [31].

As already mentioned, in CEMOVIS chemical treatment is avoided, and the specimen remains close to the native state, fully hydrated and unstained. Cryo-EM generates contrast from the protein densities themselves and allows observation at the atomic level [34]. Therefore, on the one hand CEMOVIS is regarded as the 'gold standard' of electron microscopy by some scientists $[14,35]$ but on the other hand the method is not without artefacts.

First, cryo-sections are more prone to suffer cutting artefacts than resin sections because conventional plastic sections are cut with a wet knife and the water's high surface tension allows the compressed sections to float and unfold. A liquid working the same way with the vitreous section has not been found yet, and as such cryo-sections are obtained with a dry knife. Pierson et al. [36] implemented a protective glove box in order to reduce the humidity around and within the cryo-ultramicrotome.

Secondly, knife marks, compression, chatter and crevasses become worse with increasing thickness of the sections; nonetheless some of them can be eliminated to some extent. These artefacts have been described during CEMOVIS [37] and cryo-ET studies. Knife marks are the mildest of the cutting artefacts and have no negative impact on the resolution of the observable image or quality of the $3 \mathrm{D}$ reconstruction [38]. A periodic variation in section thickness along the cutting direction, so called chatter, can be reduced by increasing the cutting speed [37]. Crevasses depend on the cutting parameters such as feed, cutting speed and the knife angle $[32,37]$ and can be minimized by reducing the thickness of sections below $70 \mathrm{~nm}$ [38]. According to Al-Amoudi, compression (30-60\%) is the most prominent cutting artefact in cryo-sectioning and is dependent on the sample [9, 38, 39]. It involves the shortening and thickening of sections and leads to a loss of resolution. To minimise this problem, it is recommended to decrease the knife angle [40] and keep the diamond knife scrupulously clean [41]. The application of an oscillating cryo-knife is an alterna- 
tive way to reduce compression [40]. Unfortunately, none of the aforementioned adjustments can completely eliminate compression.

Thirdly, after cryo-sectioning vitreous sections are attached to the EM grid support film. Using a polished metal stamping tool, the integrity of the vitreous ribbon and individual sections is altered. Moreover, this method is not adequate for proper attachment of cryo-sections to the support film. Pierson et al. [36] introduced electrostatic charging for attachment, which is devoid of stamping-related artefacts, but it cannot guarantee uniform attachment of cryo-sections to the carbon film. Consequently, the sections can be affected by the beam exposure and may move during image acquisition [38]. However, the recent developments in vitreous cryo-sectioning permit the application of this technique to study different samples. The comparison between the images obtained using a conventional preparation and CEMOVIS showed differences in the organization of bacterial DNA and cell wall of Mycobacterium smegmatis [35] and Shigella flexneri [42] and presented new insights into the morphology of bacteria [32, 43-45]. This technique enabled to show details of the design of melanosomes [46], the human skin barrier [47] and the molecular architecture of cadherins in native epidermal desmosomes [34].

\section{Cryo-Focused Ion Beam for thinning vitreous sample}

A fundamentally different method for thinning vitreous samples is Focused Ion Beam (FIB) micromachining. FIB instruments were primarily developed for material science applications such as semiconductor devices modifications, to fabricate optoelectronic components or sample preparation for high resolution TEM imaging [48, 49]. During cryo-FIB milling, the vitreous sample is maintained in a vacuum at low temperatures and is irradiated by the Focused Ion Beam, usually gallium $\left(\mathrm{Ga}^{+}\right)$ions. The controlled bombardment of the sample with a Focused Ion Beam enables to remove material with very high precision from the specimen surface through the process of sputtering [50]. However, the interaction of gallium ions with vitreous material must be taken into consideration. In the preliminary study, Marko et al. [51] proved that heat transfer to vitreously frozen water during FIB milling, with current of $10 \mathrm{pA}$ and acceleration of $30 \mathrm{kV}$, did not cause devitrification. Another result of the interaction of the Focused Ion Beam with vitrified biological material is an implantation layer of gallium ions. Simulations indicate that the ion implantation layer in a vitreous material is in the range of $10-20 \mathrm{~nm}$ [52]. Indeed, in comparison with the crevasses found in 100-300 nm thick vitreous section, the thickness of the implantation layer is much thinner. Furthermore, the angle of incidence, along the surface of the support, should be low to minimize the deposition effect of milled material during the milling process.

All experimental steps, ranging from vitrification, cryo-FIB to visualization in cryo-EM, have to be kept below the devitrification point of $-135^{\circ} \mathrm{C}$. A critical issue is to avoid additional ice contamination and prevention of other potential damage during the sample transfer and handling steps. Thus, a preparation system to mount the grids (i.e. appropriate holders, transfer devices for insertion and extraction of the samples) are generally excogitated mainly for specific applications. The process of sample thinning is performed in the Dual Beam microscopes, i.e. a combination of FIB with Scanning Electron Microscopy (SEM), enables to select area of interest and guide the milling process. During the thinning process high current is used to remove bulk material, while low current permits further thinning and obtaining final geometry [53]. The Cryo-FIB technique was used to study the structure of E. coli, M. smegmatis, S. cerevisiae, D. discoideum, HeLa and neuronal cells vitrified by Plunge Freezing [54-60] and Aspergillus niger spores and yeast vitrified via High Pressure Freezing [57, 61, 62].

Depending on the sample size and feature of interest, different preparation strategies are required. Possible FIB-milling strategies include parallel milling, wedge-shaped milling and more sophisticated cryo-lamellas. During parallel milling, the Focused Ion Beam is parallel to the EM grid surface. Alternatively, the incident ion beam mills the sample at oblique angles, resulting in a wedge-shaped area. In order to obtain sufficiently large areas for imaging, the shallow angles should be small $\left(<10^{\circ}\right)$. This type of geometry is dedicated to small bacterial cells or relatively small eukaryotic cells. During foregoing cryo-FIB approaches, material along the $\mathrm{z}$-axis is lost that makes it impossible to analyse structures of interest located deep in cellular volumes. In consequence, thinning of large mammalian cells and tissues remains a challenge. A solution for this issue is milling vitrified cells into a lamella, which enables to open a window into the interior of the cell. This can be done by micro-machining areas below and above the region of interest, leaving a thin enough area for imaging by TEM. The obtained electron transparent membrane is supported by the surrounding unmilled cell and ice. The width of the lamella should not exceed more than two thirds of the cell's visible width [56]. This approach gives access to anywhere in the sample through exclusionary selection of the milling areas. 
An alternative method to obtain lamellas is a traditional FIB lift-out method used in material science. This method had been deemed impossible because of technical aspects [57]. However, deployment of cryogenic platinum deposition [63] and the adaptation of nanomanipulators to cryogenic conditions enable to implement the lift-out method in the vitreous sample preparation field [57]. After identification of a feature of interest through SEM imaging, the sample is cryo-coated with platinum. The latter step protects the chosen area from undesirable ion beam erosion, and preserves topographical features against re-deposition of milled material and curtaining effects [63]. Next, two trenches are milled on each side of the lamella and the bottom part of the obtained structure is once again milled, leaving only two small bridges connecting the lamella to the bulk. The cooled nanomanipulator is attached to the lamella by cryo-platinum deposition followed by sputtering away the bridges holding the lamella to the bulk. The lamella is lifted out from the sputtered trenches, moved to the TEM grid and welded to a support with cryo-platinum deposition. The nanomanipulator is cut out and the lamella is finally thinned to the desired thickness.

A slightly different strategy is applied for samples vitrified by HPF. Samples can be vitrified both in copper tubes [61] and in membrane carriers [62]. Initially, either the tip of the copper tube or membrane carrier has to be trimmed with the cryo-ultramicrotome to a wedge shape in order to expose a frozen-hydrated material, which is covered with a protection layer of platinum. A lamella with the required dimensions and thickness is obtained during an iterative milling process under different currents.

In general, identifying and targeting specific sites for milling in case of smaller organisms is relatively easy and efficient. On the contrary, large vitrified eukaryotic cells, for example HeLa cells, are embedded in amorphous ice with significantly varying thickness that results from heterogeneity in cell morphology and size. Therefore, vitrified material is difficult to find and distinguish from the ice background by SEM. In order to expose large material embedded in the ice, Rigort et al. [55] adopted a cryo-planning method to generate large, homogeneously thin samples. Furthermore, a combination of light and electron microscopy can be used to expedite and widen the search for features of interest. The combination of specific fluorescent labelling of structure permits to localize features of interest of vitrified specimens under cryo-fluorescence microscope and subsequent imaging with backscattered electrons within the SEM. This approach significantly enhances finding and targeting molecules with a low number of copies or smaller structures for FIB milling [55]. Another solution is the culturing of cells on EM finder grids and taking optical images of the cells of interest before vitrification and cryo-FIB milling [59].

On the one hand, thinning samples by cryo-FIB gives unique possibilities to study structures buried deep inside cellular volumes and for selective thinning of the sample. Moreover, mammalian cells can grow directly onto the substrate in native conditions, without the need of additional steps like cell trypsinization or scrapping. Depending on the need of different geometries, thickness $(<100-500 \mathrm{~nm})$ and size of the vitreous material, cryo-EM or cryo-ET studies can be chosen. On the other hand, the FIB milling technique is time consuming and requires correlative solutions in order to localize cells on the grid in case of larger cells. Otherwise, the process of sampling takes more time and involves milling of many adjacent places in order to find features of interest. Another important point is the need of very complex transfer systems and handling steps between devices, thus the risk of ice contamination. On the surface of the milled vitreous samples milling artefacts occur, resulting from deposition of milled material. The artefacts are characteristic of milled regions and they are not present in all samples. Interestingly, the occurrence of the artefacts is not interrelated with milling currents or other parameters of the process $[58,59]$. Uneven vertical striations, the so called curtaining effect, is another artefact produced from different sputtering rates as a consequence of compositional changes within the vitreous sample $[55,59]$. The advantage of CEMOVIS over the cryo-FIB technique is the capability to prepare tissue samples in a more controllable manner. During the cryo-FIB thinning process, part of the material is physically destroyed. CEMOVIS permits to obtain serial cryo-sections, and therefore information along the $\mathrm{z}$-axis is not entirely lost.

The cryo-FIB technique is still under development; however, some interesting results have been achieved. In E. coli cells Wang and co-workers [59] found a new structural feature as invagination of the cytoplasmic membrane curves into both periplasmic and cytoplasmic spaces. Rigort et al. [56] present the potential of using cryo-FIB during structural studies of nuclear pore complexes in situ. Obtained results allow pushing resolution to the limits and opening new possibilities for microscopic studies of eukaryotic cells.

A characteristic feature of vitreously frozen material is poor contrast, due to the absence of staining with heavy metal salts. As a result of the nature of the vitreous sample, the main obstacle is low signal-to-no- 
ise ratio. This fact stems from the low phase contrast, which is based on small differences in the density and uniform distribution of the native cellular components. Another issue is the plethora of overlapping information, which results from equal distribution of the structures through the entire thickness of the sample. Additionally, vitreous material is beam sensitive, therefore a too high dose of electrons leads to the 'bubbling' (the specimen seems to be boiling and turning into small bubbles which disappear under the beam) and moving of the sections [13]. Unquestionably, computer control of the microscope is a crucial step to obtain full information from the vitreous sections. Huge progress in the computing systems and electron microscopy technologies permits to introduce low-dose mode, to minimize the total electron dose, and electron tomography technique which give insight into the three dimensional structure of the cell. For the description of the electron tomography technique in detail and its computational aspects, such as image alignment and 3D reconstruction, post processing, analysis and interpretation, the reader is refereed to exemplary works [25, 64-72].

The main disadvantage of vitreously frozen specimens is the uselessness of on-section immunogold labelling, because it requires ambient conditions to work. Therefore, the Tokuyasu technique and freeze substitution followed by resin embedding are complementary techniques to the vitrified sample.

\section{Freeze Substitution}

Freeze Substitution (FS) is a cryo-fixation method which bridges the gap between the vitreous material and conventional plastic embedding on one hand and room temperature ultramicrotomy on the other. Freeze substituted and vitreous samples are very complementary [38]. Resin sections permit to obtain an excellent overview of the cell ultrastructure with enhanced contrast of the object of interest. Information obtained from cryo-EM images can complement the images obtained from resin sections. Moreover, resin in comparison with vitreous sections enables the analysis of larger sample areas, is more stable in the electron beam and is easier to obtain. Last but not least, resin sections permit post-labelling with gold nanoparticles. This method was introduced for light microscopy by Simpson [73] and in the following years further developed in the field of electron microscopy [74-76].

The process of Freeze Substitution $[5,77]$ is performed at low temperature, yet above the devitrification temperature. Presumably, during the FS process sequential transformation from the vitreous state to cubic ice and from cubic to hexagonal ice preserve the biological structures without any segregation [9]. Low temperatures result in a reduction of the extraction of lipids and aggregation of protein [78], avoiding osmotic effects and chemical artefacts which result from the penetration and diffusion of fixative [79-81]. Freeze Substitution consists of dehydration and chemical fixation followed by embedding in resins. In the first step, a sample after cryo-immobilisation is dehydrated by organic solvents, such as acetone, methanol or ethanol. This step typically takes place in the temperature range from $-78^{\circ} \mathrm{C}$ to $-90^{\circ} \mathrm{C}$. In the second step, the biological material can be slowly infiltrated with nonreactive fixatives in chosen organic solvents in the same temperature as in the first step. As soon as the temperature is raised, fixatives start to react in situ, between $-90^{\circ} \mathrm{C}$ and $-30^{\circ} \mathrm{C}$. The main constituents of fixative solutions are aldehydes, $\mathrm{OsO}_{4}$ and uranyl acetate (UA) in mixed configurations in acetone or alcohols. It is worth mentioning that $\mathrm{OsO}_{4}$ at low temperature does not react as protease, but fixes unsaturated chains of plasma membrane fatty acids. Alternatively, Muller and Matsko showed that instead of the above mentioned stabilizing agent, reactive epoxy resins are an interesting alternative in morphological studies [82]. A characteristic feature after cryo-fixation is a weaker contrast of the sample, especially of membranes against more electron dense background - i.e. 'reverse contrast' [83]. In order to enhance membrane contrast to the substitution medium, small amounts of water may be added [84]. However it is possible to wash out the antigens, which should be taken into account at the immunocytochemistry level [85]. Other media may contain tannic acid in acetone $[86,87]$ in combination with $\mathrm{OsO}_{4}[88]$, different combinations of UA, glutaraldehyde and $\mathrm{OsO}_{4}[83,89,90]$ or potassium permanganate [89]. The duration of substitution depends on the chosen medium and the sample but the range of time fluctuates between a few hours and a few days.

It is worth mentioning the latest McDonald and Webb's studies, with subsequent McDonald's [91] modifications, where FS can be obtained in 3 hours or less [92]. After the FS process, the sample is embedded in resins. Epoxy resins are dedicated to the morphological approach by virtue of good preservation of ultrastructure, a larger stability in the electron beam and ease of sectioning. Methacrylic resins are used for immunocytochemical research because of their properties such as impregnation and UV polymerisation at low temperatures, lack of sample cross-linking and higher roughness of the section surface [2,76, 93]. Interestingly, total processing time from vitrification followed by freeze substitution and resin embedding 
to section can be completed in 6 hours [91, 94]. Results obtained by above rapid specimen preparation procedures was comparable to standard FS and resin embedding methods that take days to complete.

A combination of HPF and FS followed by resin embedding offers tremendous research capabilities in cell and tissue biology. E.g., studies on the aorta prepared by HPF provided a new basis for understanding of cell/cell and cell/matrix cross-talk in aortic media [95] and new data about structure and function of Weibel-Palade body in endothelial cells were obtained $[96,97]$. Cryo-fixation with immunogold labelling was used for subcellular localisation of $\mathrm{H}^{+} / \mathrm{K}^{+}$-ATPase in gastric parietal cells [98], immunolocalisation of collagen in human articular cartilage [99] and of Connexin 43 proteins in rat myocardium [100]. It is worth mentioning that cryo-fixation in combination with ET [16, 66, 101] and CLEM [102-104] gives a chance to understand not only cell ultrastructure but also dynamics of the cellular processes.

\section{Tokuyasu cryo-sectioning method}

The Tokuyasu technique was introduced in the 1970's by Tokuyasu, using a cryo-ultramicrotome developed by A. Christensen $[105,106]$. According to his protocol the biological material is chemically fixed with low concentrations of aldehydes, cryo-protected in sucrose, frozen in liquid nitrogen and sectioned at low temperature (ca. $-100^{\circ} \mathrm{C}$ ) in a cryo-ultramicrotome with a dry knife. Cryo-sections are retrieved from the knife edge, thawed and transferred to microscope slides or formvar carbon-coated grids. Semi-thin cryo-sections can be used for immunofluorescence microscopy [107]. Thin sections may be directly observed in EM, labelled (mostly by antibodies) [108] (Figure 2A), or used for mRNA localisation by in situ hybridization [109]. After labelling, unstable and delicate sections are embedded in a thin film of plastic containing a contrasting agent $[106,110]$. Over the years, the technique has been improved and perfected by its inventor and other researchers [111-115]. What makes this method so preferred? The Tokuyasu method eliminated harmful processes i.e. dehydration by organic solvents and embedding in resin. Dehydration was replaced by cryo-protection which reduces the water content in cells resulting in partial dehydration. However, antigens still remain in their natural aqueous environment, which is important for antigens sensitive to ethanol. Additionally thawed cryo-sections enable better access to the antigens (particularly rare ones) for the probes because they are not embedded in resin, that is to say a high density matrix. These advantages determined that cryo-sectioning of chemically fixed and cryo-protected samples became a widely used method for immunolabelling $[77,116]$.

Unfortunately, the technique has drawbacks. A limitation inherent to the Tokuyasu cryo-sectioning method is chemical fixation at ambient temperature. On the one hand, it is a prerequisite to stabilize the cell structure prior to cryo-protection and cryo-sectioning in order to reduce extraction of cytoplasmic proteins. On the other hand, aldehyde fixation is a slow and selective process which results in $\mathrm{pH}$-related and osmotic changes in the different organelles [117]. Besides, it should be mentioned that not all specimens are suited for this method. The penetration of the fixatives is hampered in samples containing intercellular air spaces or large vacuoles (leaves), cell walls (plants, fungi) or cuticles, hydrophobic surfaces (insects, nematodes) [114]. In consequence, improperly cross-linked molecules can be dislocated or get lost which could lead to misconception about their internal organization $[117,118]$. The main advantage of the Tokuyasu technique, however, can also be a disadvantage because the absence of resin matrix may result in the partial extraction of the material.

Despite the drawbacks for several types of biological specimens, the Tokuyasu cryo-sectioning technique is a valuable and preferred immunolabelling method in combination with the highly efficient immunogold labelling [77]. Therefore many researchers have applied this technique to study various biological objects [35, 110, 117-122].

\section{At the edge of possibilities - hybrid techniques}

It has been well documented that cryo-fixation by HPF combined with FS and resin embedding can significantly improve the preservation of ultrastructure and antigenicity [123, 124]. Nevertheless, not all antigens can be immunolabelled in such a way due to a limited number of accessible antigens at the resin section surface (especially important in locating rare antigens) [125]. As it is known the Tokuyasu cryo-sectioning is the most efficient, localization technique for immunolabelling. Therefore different groups of scientists have tried to establish a new solution using combinations of different cryo-techniques. Hybrid techniques have been developed in response to difficulties which have occurred during the sample preparation process. They include the advantages of two or more techniques creating new methods with prospective research potential.

Hybrid techniques include the method which introduces the initial chemical fixation prior to HPF and FS (Hybrid Fixation Technique). The aldehyde fixation is necessary in order to minimize structural 
damage during long dissection times. This procedure is intended for the labile tissue (especially the brain) exposed to damage due to lack of oxygen at the time of collection. Sosinsky et al. [87] showed that chemical pre-fixation before HPF and FS followed by resin embedding provided a better preservation of ultrastructure than a single chemical fixation. However, exposure of fresh, microdissected tissue to highly concentrated cryo-protectants can lead to osmotic stress and physical damage [126]. Using aldehyde fixation before HPF-FS and resin embedding, Ewald et al. [127] achieved high-quality ultrastructural preservation of cell membranes in multilayered epithelium. If we have to deal with biopsies, immediate processing of samples by HPF may not always be possible and chemical fixation is the only alternative, thus, the hybrid fixation method seems to be a good solution for this problem. Work of Venter et al. [128] proved that ultrastructure after prolonged storage in fixatives and subsequent HPF-FS followed by resin embedding was better retained in comparison with conventional sample processing.

Liou et al. [112] and van Donselaar et al. [120] developed a technique that combines high-efficiency of Tokuyasu cryo-section labelling with initial cryo-fixation by HPF. This can be achieved in two ways: the first is the Section Fixation Method (SFM) (Figure 2B), in which native ultrathin cryo-sections are chemically fixed (in a mixture of sucrose/methyl cellulose/ /glutaraldehyde/formaldehyde/uranyl acetate) and subsequently immunolabelled. It has turned out that this method is impractical in the Immuno-Electron Microscopy (IEM) standard research (well-preserved material has been obtained only on a small area of the section's surface). According to the authors, it was probably due to the critical interweaving of thawing and chemical fixation $[112,120]$.

Another hybrid technique is the ReHydration Method (RHM) in which cryo-fixed material is subjected to Freeze Substitution, subsequent rehydration, cryosectioning following the Tokuyasu method and finally immunogold labelling (Figure 2A). This method has been applied for tissues and mammalian cells [120] and difficult to chemically fix material such as plant, nematodes and insects tissues $[117,118]$.

It has been shown that the hybrid technique is superior to the conventional method for the following reasons. Cryo-immobilization is a fast and non-selective process and therefore reduces the changes linked to a slowed down diffusion of fixatives during conventional fixation in ambient temperature. Freeze Substitution enables the use of glutaraldehyde, uranyl acetate or $\mathrm{OsO} 4$ as primary fixatives and these approaches resulted in the good preservation of the cellular ultrastructure as well as the antigenicity. It has been proved that antigens which do not react with aldehydes and are sensitive to chemical processes maintain their activity despite the use of high concentrations of fixatives. The hybrid method is suitable for antigens that are sparse and sensitive to embedding in resin. The visibility of the cellular membranes was enhanced when the Freeze Substitution medium was supplemented with low amount of water [117, 120]. According to Stierhof and Kasmi the water's effect on membrane preservation was not observed in all plant tissues. Therefore, they preferred $\mathrm{OsO}_{4}$ fixation alone during FS, because it resulted in sufficient visibility of the ultrastructural details of different plant tissues [118]. The improved preparation methods combined with sensitive marker systems, such as $1 \mathrm{~nm}$ gold markers, allow detection of sparse antigens.

It should be mentioned that immunofluorescence microscopy may benefit from the hybrid technique: the good quality and adequate section thickness guarantee high resolution data. The simultaneous detection of several fluorescence markers together with labelled antigens is possible. The fluorochromes do not affect the binding properties of the antibodies which results in high selectivity and sensitivity in this method. If the sample does not emit any fluorescent signal in immunolabelling experiments, it means that immunogold labelling for TEM does not make sense due to the lower sensitivity of TEM markers (gold nanoparticles) in contrast to the fluorescent markers [118]. However, a serious disadvantage of the method is its long duration.

Sabanay et al. [129] presented a new approach to obtain Vitrified Frozen Sections (VFS) for high resolution ultrastructural analysis of cells and tissues (Figure 2A). This technique combines the classic Tokuyasu method with re-vitrification in liquid ethane of the sections collected on the EM grid. The immunolabelling step was performed following the rinsing of the sections and prior to their embedding in ice. Twenty years later Bokstad et al. [130] applied this technique to 3D imaging. This experiment used comparatively thick sections (300-400 $\mathrm{nm}$ ) with acceptable structural preservation of the tested sample which enabled the reconstruction of the 3D structure by cryo-ET. The VFS technique avoids artefacts associated with the CEMOVIS approach due to the thickness and also by thawing the sections on the grid prior to the vitrification process.

Two new methods for the fixation of sections from cryo-immobilized samples for Immuno-TEM were developed by Karreman et al. [131]. These high -speed fixation techniques known as VIS2FIX are an alternative to the more time-consuming approaches mentioned above. In the first step of the VIS2FIX 


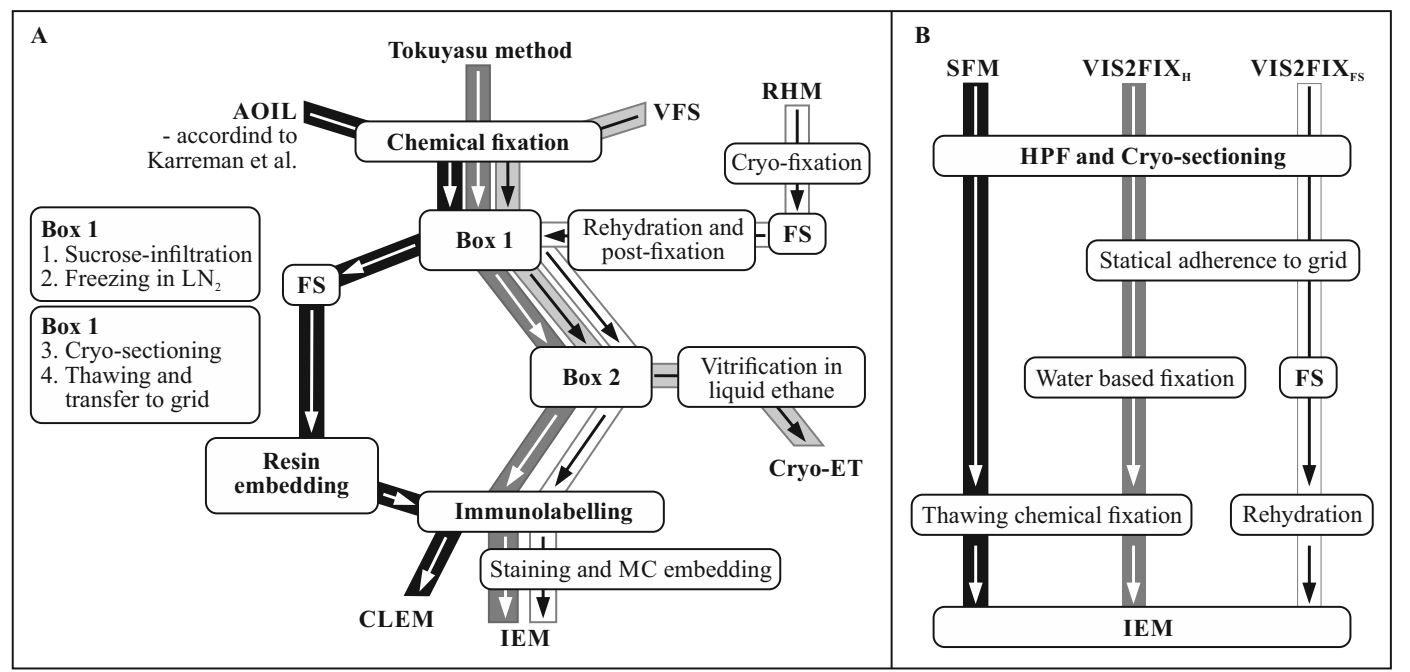

Figure 2. The flow chart shows the steps involved in Hybrid Technique. A. Chemical fixation is a prerequisite to the Tokuyasu, VFS and AOIL methods. The Tokuyasu method contains the steps shown in the Box1 and Box 2 followed by the final labelling step. The VFS method includes the Box1 and Box2, the final step of this method is vitrification in liquid ethane, subsequently, the sample can be analysed by cryo-ET. The AOIL method is characterized by Box1, (2) Freeze Substitution (FS) with resin embedding, (3) labelling, finally the sample can be analysed in IEM or iLEM. The RHM method starts from cryofixation, there follows (1) FS; (2) rehydration and postfixation; (3) Box1; (4) Box2; (5) immunolabelling; (6) staining; (7) analysing in IEM. Box 1 includes the following steps: (1) sucrose infiltration; and (2) freezing in liquid nitrogen $\left(\mathrm{LN}_{2}\right)$. Box 2 involves: (3) cryo-sectioning; (3) cryo-sectioning; (4) thawing and transfer to grid. B. The SFM and theVIS2FIX methods are based on cryo-immobilization and cryo-sectioning. Subsequently, in the SFM sections are simultaneously thawed and fixed, then labelled and finally analysed in IEM. In the VIS2FIX sections attached to the grids are preserved under different conditions, more details are describes in the text. In the last step the labelled sample may be viewed in IEM and CLEM

process, vitreous sections (VIS) of the cryo-immobilized sample are cut and statically adhered to the grid. Next, the sections on the grid are fixed in two ways (FIX); VIS2FIXFS, and VIS2FIXH (Figure 2B). VIS2FIXFS is based on FS and subsequent rehydration of the sections. In VIS2FIXH („H”-hydrated) the grids with sections are placed on a water based frozen fixative which is then thawed and fixed in liquid fixative. The VIS2FIX technique reduces the time needed for preparing samples and allows the use of a wide variety of fixatives which enlarge the research potential, e.g. the VIS2FIXH preserves the neutral lipids. The fixation and retention of neutral lipids is a unique feature of the VIS2FIXH method. Both techniques provide good membrane contrast and excellent preservation of vesicles especially in the Golgi area. The lack of embedding medium does not cause the loss of epitopes. The VIS2FIX offers new possibilities for IEM (the cross-linked antigens are more accessible because only a thin layer of section is fixed using this method) and for the integrated Laser and Electron Microscopy (iLEM - a novel tool for correlative microscopy combining fluorescence microscopy and TEM in a single setup). Both methods provided high fluorescence signals and abundant immunogold labelling.
The iLEM allows for quick correlation between fluorescence microscopy and transmission electron microscopy in the imaging of a sample. The optical-imaging mode is used to identify fluorescent markers and then the region of interest (ROI) is analysed at high resolution in the TEM mode. In this way, the time-consuming relocation of the ROI across microscopy platforms is avoided (with non-integrated solutions for correlative microscopy the sample needs to be transferred from one imaging set-up to another and specialised procedures are required to correlate the results) $[132,133]$.

In preparing specimens for analysis in the iLEM, two distinct and conflicting demands need to be met: the preservation of cellular ultrastructure and bright fluorescent labelling. These requirements, which a sample must meet to be imaged in iLEM, have become an impulse to develop new sample preparation techniques or to optimize the ones that exist. It is commonly known that if heavy metal and fluorescent label particles are localized at the distance of $\sim 100 \AA$ from each other, quenching of the fluorescence signal may occur [132]. In order to prevent this, the material must be prepared in such a way that increasing the distance between markers' particles is possible. Karreman and co-workers [134] used a procedure in which chemically 
Table 1. Hybrid techniques and its advantages

\begin{tabular}{|c|c|}
\hline Hybrid technique & Characteristic features \\
\hline $\begin{array}{l}\text { Hybrid Fixation Technique } \\
\text { Purpose: stabilization of dedicated labile } \\
\text { and fragile tissues }\end{array}$ & $\begin{array}{l}\text { Minimizes structural damage due to anoxia and excision in labile tissues }{ }^{1} \\
\text { Convenience in preservation of biopsies }\end{array}$ \\
\hline $\begin{array}{l}\text { ReHydration Method } \\
\text { Purpose: suitablefordifficult-to-fix specimens } \\
\text { and antigens }\end{array}$ & $\begin{array}{l}\text { Eliminates the limitations related to diffusion of the fixatives into problematic } \\
\text { samples }^{2} \\
\text { Allows the application of different fixatives and their combinations } \\
\text { The reagents actgentlyat low temperatures, } \mathrm{OsO}_{4} \text { is lessproteolytical to antigens } \\
\text { Antigens remain in an aqueous environment prior to immunolabelling, i.e. im- } \\
\text { proves the accessibility of epitopes } \\
\text { The visibility of membranes can be improved byadding water to FS medium }{ }^{3} \\
\text { Can be used for in situ hybridization for CLEM }\end{array}$ \\
\hline $\begin{array}{l}\text { VFS Method } \\
\text { Purpose: structural research by ET }\end{array}$ & $\begin{array}{l}\text { Enables direct examination of unstained, hydrated sections in conjunction with } \\
\text { immunogold labelling } \\
\text { The sample remain hydrated during preparation and examination } \\
\text { This } \\
\text { Thickness of vitrified ice layer does not change under vacuum column } \\
\text { Offers a simple approach for 3D reconstructing thick volumes of hydrated frozen } \\
\text { sections } \\
\text { Allows obtainingappropriate thicknesssections and circumvent artefacts associa- } \\
\text { ted with CEMOVIS }\end{array}$ \\
\hline $\begin{array}{l}\text { VIS2FIX Methods for IEM } \\
\text { Purpose: newpotential for conventional } \\
\text { immuno-TEM, CLEM and ET }\end{array}$ & $\begin{array}{l}\text { Fast, reproducible and many fixatives can be tested on single sample } \\
\text { Unique feature of VIS2FIX } \mathrm{H}_{\mathrm{H}} \text { - preservation of the lipid droplets } \\
\text { Good membrane contrast of the ER, the nuclear envelope, the Golgi, lysosomes } \\
\text { and cristae of the mitochondria } \\
\text { Gives new possibilities for immuno-TEM } \\
\text { The labelling of covered by cross-linking epitopes is possible } \\
\text { The loss of material is not found (Forssman glycolipid was excellently labelled } \\
\text { Suited for use in CLEM (iLEM) }\end{array}$ \\
\hline $\begin{array}{l}\text { AOIL - An OptimizedImmunoLabelling } \\
\text { for iLEM }\end{array}$ & $\begin{array}{l}\text { Offers en bloc staining of the biological material before embedding in resin to } \\
\text { prevent quenching of the fluorescence }\end{array}$ \\
\hline
\end{tabular}

Numbers 1-5 indicate which cryo-technique is used in hybrid approach: ${ }^{1}$ chemical fixation, ${ }^{2}$ cryo-fixation, ${ }^{3} \mathrm{FS},{ }^{4}$ Tokuyasu cryo-sectioning, ${ }^{5}$ vitreous cryo-sectioning. AOIL according to Karreman et al., 2012.

fixed cells were embedded in $12 \%$ gelatin and cryo -protected in sucrose. The sample blocks were plunge frozen in liquid nitrogen and subsequently freeze substituted and embedded in the Lowicryl HM20 resin (Figure 2A). The material was stained during a FS process, before resin embedment. Simultaneously, an appropriate TEM fluorescent marker had been chosen (such as marker which in the vacuum conditions emits a strong fluorescence signal). Fluorophores' labelling was made on sections obtained from en bloc stained samples. As a result of this experiment, the authors established, that en bloc staining did not quench the fluorescence signal that was emitted by a given marker (TRITC) and, ultimately, guaranteed a good contrast of the analysed sample [134].

The different approaches have their own sets of advantages and might well be the methods of choice in experiments under various experimental conditions (Table 1). The advantages of the application of hybrid techniques can be summarised in a following way:

1. they enable to deal with different materials and also with those that are difficult to fix,
2. can be used when conventional fixation at ambient temperature is not satisfactory or not useful due to the inactivation of antigens and the presence of artefacts caused by slow fixative diffusion,

3. can be applied when cryo-fixation and accessibility of antigens (two in one) is required.

\section{Conclusions and perspectives}

Even if due to technological advances, transmission electron microscopes will reach the resolution of Angstrom limit, the sample preparation process will always remain a crucial issue. Technological progress and sample preparation methods are linked with each other and create a kind of feedback. Since the mystery of water vitrification was unrevealed by Dubochet and co-workers [13], various cryo-preparation methods have been developed. This discovery has also stimulated development of different instruments as the solution of specific problems which evolved during material preparation. Nowadays, the results of these developments enable vitrification of various types of 
samples. Direct observation of vitrified specimens, especially in combination with electron tomography, permits visualisation of 'near to native state' cellular architecture. The CEMOVIS technique first enabled the direct visualization of the cell ultrastructure in the vitreous state. The inherent feature of the CEMOVIS is section compression due to the different flexibility of cellular structures [135], which is difficult to correct by the specialized software. A solution for this problem was the adaptation of FIB and SEM microscopes to cryogenic conditions in order to obtain perfectly flat cryo-lamellas with no evidence of mechanical distortions. On the other hand, the research potential of cryo-techniques has been well established, which makes it possible to simultaneously exploit various preparation routes to reach the goal in mind. One excellent instance is the iLEM microscope, because this correlative technique requires the optimization of sample preparation protocols for optimal results. It was shown that a hybrid approach, a combination of the Tokuyasu technique with FS, enables to prevent the quenching effect of the contrasting agent on the immunofluorescent labelling on the section. This approach enables to localize fluorescence signals at a high resolution level. Other hybrid approaches were introduced for either difficult to fix samples or antigens (Rehydration Method and VIS2FIX method). However, depending on the sample, the Tokuyasu technique and FS followed by resin embedding rather became complementary to immuno-TEM.

Modern EM focuses on a correlative approach at different microscopic levels. Cryo-preparation techniques play a very important role during imaging of cell ultrastructure by new, powerful tomography solutions such as Serial Sectioning SEM and Correlative Array Tomography or FIB-SEM correlated with Confocal Laser Scanning Microscopy [136]. Current trends focus also on all-in-one solutions. The combination of FIB with TSEM (Transmission Scanning Electron Microscopy) microscopes enables to obtain cryo-lamellas with navigation in the SEM mode and higher magnified images in transmission mode. TSEM microscopes permit to check the quality of the frozen material by orientation contrast or by Electron BackScatter Diffraction detectors [62]. Finally, Cryo-iLEM, as a new approach proposed by Faas et al. [137], increases the successful correlation rate and permits to avoid contamination and damage of vitrified samples during transfer between different microscopes.

The combination of TSEM with fluorescence microscopy into a single device could potentially provide, at the in situ level, assignment of location, preparation and integrity check of the cryo-lamella, and subsequent observation and tomography of the sample.

However, it must be taken into account, that conventional TEM has a well established position in biological and medical sciences because of the possibility to study samples with a large size. Conventional TEM helps to make diagnosis in different kinds of illness, for example kidney glomerular disease and primary ciliary dyskinesia. A very interesting example which proves the research capabilities of conventional TEM was the discovery of telocytes (or re-discovery of Cajal cells) found in different tissues [138, 139]. Therefore, the choice of the sample preparation option depends on the size of the specimens being studied, how the sample is obtained (for example in a hospital) and what type of study will be carried out.

\section{Acknowledgment}

The authors are deeply indebted to Jacob Tyszka for improving the English style of the manuscript.

\section{References}

1. 1. Yakovlev S, Downing KH. Freezing in sealed capillaries for preparation of frozen hydrated.J Microsc. 2011;244:235-247.

2. Kellenberger E. The response of biological macromolecules and supramolecular structures to the physics of specimen cryopreparation. In: Steinbrecht RA, Zierold K(eds.). Cryotechniques in biological electron microscopy. Berlin, Heidelberg: Springer 1987:35-63.

3. Dubochet J, Sartori Blanc N. The cell in absence of aggregation artifacts. Micron. 2001;32:91-99.

4. Lucić V, Förster F, Baumeister W. Structural studies by electron tomography: from cells to molecules. Annu Rev Biochem. 2005;74:833-865.

5. Hurbain I, Sachse M. The future is cold: cryo-preparation methods for transmission electron microscopy of cells. Biol Cell. 2011;103:405-420.

6. Studer D, Humbel BM, Chiquet M. Electron microscopy of high pressure frozen samples: bridging the gap between cellular ultrastructure and atomic resolution. Histochem Cell Biol. 2008;130:877-889.

7. Massover WH. New and unconventional approaches for advancing resolution in biological transmission electron microscopy by improving macromolecular specimen preparation and preservation. Micron. 2011;42:141-151.

8. Vanhecke D, Werner G, Studer D. Close-to-Native ultrastructural preservation by high pressure freezing. Methods Cell Biol. 2008;88:151-164.

9. Dubochet J. The physics of rapid cooling and its implications for cryoimmobilization of cells. Methods Cell Biol. 2007;79:7-21.

10. Taylor KA, Glaeser RM. Electron diffraction of frozen, hydrated protein crystals. Science. 1974;186:1036-1037.

11. Bruggeller P, Mayer E. Complete vitrifcation in pure liquid water and dilute aqueous solutions. Nature. 1980;288:569-571.

12. Dubochet J, McDowall AW. Vitrification of pure water for electron microscopy. J Microsc. 1981;124:3-4.

13. Dubochet J, Adrian M, Chang JJ et al. Cryo-electron microscopy of vitrified specimens. Q Rev Biophys. 1988;21:129-228. 
14. Dubochet J. Cryo-EM-the first thirty years. J Microsc. 2012;245:221-224.

15. Costello MJ. Cryo-electron microscopy of biological samples. Ultrastruct Pathol. 2006;30:361-371.

16. Gan L, Jensen GJ. Electron tomography of cells. $Q$ Rev Biophys. 2012;45:27-56.

17. Tivol WF, Briegel A, Jensen GJ. An Improved Cryogen for Plunge Freezing. Microsc Microanal. 2008;14:375-379.

18. Moor H, Riehle U. Snap-freezing under high pressure: A new fixation technique for freeze-etching. Proc Fourth Europ Reg Conf Elect Microsv. 1968;2:33-34.

19. Gilkey JC, Staehelin LA. Advances in ultrarapid freezing for the preservation of cellular ultrastructure.J Electron Microsc Tech. 1986;3:177-210.

20. McDonald K. Cryopreparation methods for electron microscopy of selected model systems. Methods Cell Biol. 2007;79:23-56.

21. Leunissen JLM, Yi H. Self-pressurized rapid freezing (SPRF): a novel cryofixation method. J Microsc. 2009;235:25-35.

22. Szobota SA, Rubinsky B. Analysis of isochoric subcooling. Cryobiology. 2006;53:139-142.

23. Han H-M, Huebinger J, Grabenbauer M. Self-pressurized rapid freezing (SPRF) as a simple fixation method for cryo-electron microscopy of vitreous sections. J Struct Biol. 2012;178:84-87.

24. Medalia O, Weber I, Frangakis AS, Nicastro D, Gerisch G, Baumeister W. Macromolecular architecture in eukaryotic cells visualized by cryoelectron tomography. Science. 2002;298:1209-1213.

25. Koning RI, Koster AJ. Cryo-electron tomography in biology and medicine. Ann Anat. 2009;191:427-445.

26. Fernandez-Moran H. Application of the ultrathin freezing sectioning technique to the study of cell structures with the electron microscope. Ark Fys. 1952;4:471-491.

27. Bernhard W, Leduc EH. Ultrathin frozen sections. I. Methods and ultrastructural preservation. J Cell Biol. 1967;34:757-771.

28. Christensen AK. Frozen thin sections of fresh tissue for electron microscopy, with a description of pancreas and liver. J Cell Biol. 1971;51:772-804.

29. McDowall AW, Chang JJ, Freeman R, Lepault J, Walter CA, Dubochet J. Electron microscopy of frozen hydrated sections of vitreous ice and vitrified biological samples. J Microsc. 1983;131:1-9.

30. Hsieh C, Marko M, Frank J, Mannella C. Electron tomographic analysis of frozen-hydrated tissue sections. J Struct Biol. 2002;138:63-73.

31. Al-Amoudi A, Chang JJ, Leforestier A et al. Cryo-electron microscopy of vitreous sections. EMBOJ. 2004;23:3583-3588.

32. Al-Amoudi A, Norlen L, Dubochet J. Cryo-electron microscopy of vitreous sections of native biological cells and tissues. J Struct Biol. 2004;148:131-135.

33. Richter K. A cryoglue to mount vitreous biological specimens for cryoultramicrotomy at $110 \mathrm{~K}$. J Microsc. 1994;173:143-147.

34. Al-Amoudi A, Díez DC, Betts MJ, Frangakis AS. The molecular architecture of cadherins in native epidermal desmosomes. Nature. 2007:450:832-837.

35. Bleck C, Merz A, Gutierrez MG et al. Comparison of different methods for thin section EM analysis of Mycobacterium smegmatis. J Microsc. 2010;237:23-38.

36. Pierson J, Fernández JJ, Bos E et al. Improving the technique of vitreous cryo-sectioning for cryo-electron tomography: electrostatic charging for section attachment and implementation of an anti-contamination glove box. J Struct Biol. 2010;169:219-225.
37. Al-Amoudi A, Studer D, Dubochet J. Cutting artefacts and cutting process in vitreous sections for cryo-electron microscopy. J Struct Biol. 2005;150:109-121.

38. Bouchet-Marquis C, Hoenger A. Cryo-electron tomography on vitrified sections: a critical analysis of benefits and limitations for structural cell biology. Micron. 2011;42:152-162.

39. Pierson J, Vos M, McIntosh JR, Peters PJ. Perspectives on electron cryo-tomography of vitreous cryo-sections.J Electron Microsc. (Tokyo). 2011;60(Suppl. 1):S93-100.

40. Al-Amoudi A, Dubochet J, Gnaegi H, Lüthi W, Studer D. An oscillating cryo-knife reduces cutting-induced deformation of vitreous ultrathin sections. J Microsc. 2003;212:26-33.

41. Norlén L, Oktem O, Skoglund U. Molecular cryo-electron tomography of vitreous tissue sections: current challenges. |J Microsc. 2009;235:293-307.

42. Couture-Tosi E, Ranck J-L, Haustant G, Pehau-Arnaudet G, Sachse M. CEMOVIS on a pathogen: analysis of Bacillus anthracis spores. Biol Cell. 2010;102:609-619.

43. Eltsov M, Dubochet J. Fine structure of the Deinococcus radiodurans nucleoid revealed by cryoelectron microscopy of vitreous sections. J Bacteriol. 2005;187:8047-8054.

44. Salje J, Zuber B, Löwe J. Electron cryomicroscopy of E. coli reveals filament bundles involved in plasmid DNA segregation. Science. 2009;323:509-512.

45. Kishimoto-Okada A, Murakami S, Ito Y et al. Comparison of the envelope architecture of E. coli using two methods: CEMOVIS and cryo-electron tomography.J Electron Microsc. (Tokyo). 2010;59:419-426.

46. Hurbain I, Geerts WJC, Boudier T et al. Electron tomography of early melanosomes: implications for melanogenesis and the generation of fibrillar amyloid sheets. Proc Natl Acad Sci U S A. 2008;105:19726-19731.

47. Iwai I, Han H, den Hollander L et al. The human skin barrier is organized as stacked bilayers of fully extended ceramides with cholesterol molecules associated with the ceramide sphingoid moiety. J Invest Dermatol. 2012;132:2215-2225.

48. Moberlychan WJ, David P, Aziz MJ, Hobler G, Schenkel T. Fundamentals of Focused Ion Beam nanostructural processing: below, at, and above the surface. MRS Bull. 2007;32:424-433.

49. Volkert CA, Minor AM. Focused Ion Beam micromachining. MRS Bull. 2007;32:389-399.

50. Giannuzzi LA, Stevie FA. Introduction to Focused Ion Beam. New York: Springer; 2005.

51. Marko M, Hsieh C, Moberlychan W, Mannella CA, Frank J. Focused Ion Beam milling of vitreous water: prospects for an alternative to cryo-ultramicrotomy of frozen-hydrated biological samples. J Microsc. 2006;222:42-47.

52. Ziegler JF, Ziegler MD, Biersack JP. SRIM — The stopping and range of ions in matter. Nucl Instruments Methods Phys Res Sect B Beam Interact with Mater Atoms. 2010;268:1818-1823.

53. Villa E, Schaffer M, Plitzko JM, Baumeister W. Opening windows into the cell: focused-ion-beam milling for cryo-electron tomography. Curr Opin Struct Biol. 2013;23:771-777.

54. Marko M, Hsieh C, Schalek R, Frank J, Mannella C. Focused -ion-beam thinning of frozen- hydrated biological specimens for cryo-electron microscopy. Nat Methods. 2007;4:215-217.

55. Rigort A, Bäuerlein FJB, Leis A et al. Micromachining tools and correlative approaches for cellular cryo-electron tomography. J Struct Biol. 2010;172:169-179.

56. Rigort A, Bäuerlein FJB, Villa E et al. Focused Ion Beam micromachining of eukaryotic cells for cryoelectron tomography. Proc Natl Acad Sci U S A. 2012;109:4449-4454.

57. Rubino S, Akhtar S, Melin P, Searle A, Spellward P, Leifer K. A site-specific focused-ion-beam lift-out method 
for cryo Transmission Electron Microscopy. J Struct Biol. 2012;180:572-576.

58. Strunk KM, Wang K, Ke D, Gray JL, Zhang P. Thinning of large mammalian cells for cryo-TEM characterization by cryo-FIB milling. J Microsc. 2012;247:220-227.

59. Wang K, Strunk K, Zhao G, Gray JL, Zhang P. 3D structure determination of native mammalian cells using cryo-FIB and cryo-electron tomography. J Struct Biol. 2012;180:318-326.

60. Lučič V, Rigort A, Baumeister W. Cryo-electron tomography: the challenge of doing structural biology in situ. J Cell Biol. 2013;202:407-419.

61. Hayles MF, de Winter DAM, Schneijdenberg CTWM et al. The making of frozen-hydrated, vitreous lamellas from cells for cryo-electron microscopy.J Struct Biol. 2010;172:180-190.

62. De Winter DAM, Mesman RJ, Hayles MF, Schneijdenberg CTWM, Mathisen C, Post JA. In-situ integrity control of frozen-hydrated, vitreous lamellas prepared by the cryo-Focused Ion Beam-scanning electron microscope. J Struct Biol. 2013;183:11-18.

63. Hayles MF, Stokes DJ, Phifer D, Findlay KC. A technique for improved Focused Ion Beam milling of cryo-prepared life science specimens. J Microsc. 2007;226:263-269.

64. McIntosh JR. Electron microscopy of cells: a new beginning for a new century. J Cell Biol. 2001;153:F25-32.

65. Frank J. Electron Tomography. Methods for Three-Dimensional Visualization of Structures in the Cell. New York: Springer; 2006.

66. Bárcena M, Koster AJ. Electron tomography in life science. Semin Cell Dev Biol. 2009;20:920-930.

67. Pierson J, Sani M, Tomova C, Godsave S, Peters PJ. Toward visualization of nanomachines in their native cellular environment. Histochem Cell Biol. 2009;132:253-262.

68. Beck M, Topf M, Frazier $\mathrm{Z}$ et al. Exploring the spatial and temporal organization of a cell's proteome. J Struct Biol. 2011;173:483-496.

69. Vanhecke D, Asano S, Kochovski Z et al. Cryo-electron tomography: methodology, developments and biological applications. J Microsc. 2011;242:221-227.

70. Fernandez J-J. Computational methods for electron tomography. Micron. 2012;43:1010-1030.

71. Briggs JA. Structural biology in situ-the potential of subtomogram averaging. Curr Opin Struct Biol. 2013;23:261-267.

72. Harapin J, Eibauer M, Medalia O. Structural analysis of supramolecular assemblies by cryo-electron tomography. Structure. 2013;21:1522-1530.

73. Simpson WL. An experimental analysis of the Altmann technic of freezing-drying. Anat Rec. 1941;80:173-189.

74. Fernandez-Moran H. Low-temperature preparation techniques for electron microscopy of biological specimens based on rapid freezing with liquid Helium II. Ann N Y Acad Sci. 1960;13:689-713.

75. Van Harreveld A, Crowell J. Electron microscopy after rapid freezing on a metal surface and substitution fixation. Anat Rec. 1964;149:381-385.

76. Humbel BM, Schwarz H. Freeze-substitution for immunocytochemistry. In: Verkleij AJ, Leunissen JLM (eds.). Immuno-gold labeling in cell biology. Boca Raton, Florida: CRC Press; 1989:114-134.

77. Möbius W. Cryopreparation of biological specimens for immunoelectron microscopy. Ann Anat. 2009;191:231-247.

78. Kellenberger E. The potential of cryofixation and freeze substitution: observations and theoretical considerations. J Microsc. 1991;161:183-203.

79. Studer D, Hennecke H, Müller M. High Pressure freezing of soybean nodules leads to an improved preservation of ultrastructure. Planta. 1992;188:155-163.
80. Sosinsky GE, Deerinck TJ, Greco R, Buitenhuys CH. Development of a model for microphysiological small nodes of Ranvier from peripheral nerves of mice reconstructed by electron tomography. Neuroinformatics. 2005:133-162.

81. Zechmann B, Müller M, Zellnig G. Membrane associated qualitative differences in cell ultrastructure of chemically and high pressure cryofixed plant cells. J Struct Biol. 2007;158:370-377.

82. Matsko N, Mueller M. Epoxy resin as fixative during freeze -substitution. J Struct Biol. 2005;152:92-103.

83. Hawes P, Netherton CL, Mueller M, Wileman T, Monaghan P. Rapid freeze-substitution preserves membranes in High Pressure frozen tissue culture cells. J Microsc. 2007;226:182-189.

84. Walther P, Ziegler A. Freeze substitution of High Pressure frozen samples: the visibility of biological membranes is improved when the substitution medium contains water. J Microsc. 2002;208:3-10.

85. Sobol MA, Philimonenko VV, Philimonenko AA, Hozák P. Quantitative evaluation of freeze-substitution effects on preservation of nuclear antigens during preparation of biological samples for immunoelectron microscopy. Histochem Cell Biol. 2012;138:167-177.

86. Siksou L, Rostaing P, Lechaire J-P et al. Three-dimensional architecture of presynaptic terminal cytomatrix. $J$ Neurosci. 2007;27:6868-6877.

87. Sosinsky GE, Crum J, Jones YZ et al. The combination of chemical fixation procedures with high pressure freezing and freeze substitution preserves highly labile tissue ultrastructure for electron tomography applications. J Struct Biol. 2008;161:359-371.

88. Jiménez N, Vocking K, van Donselaar EG, Humbel BM, Post JA, Verkleij AJ. Tannic acid-mediated osmium impregnation after freeze-substitution: a strategy to enhance membrane contrast for electron tomography. J Struct Biol. 2009;166:103-106.

89. Giddings TH. Freeze-substitution protocols for improved visualization of membranes in High Pressure frozen samples. J Microsc. 2003;212:53-61.

90. Hillmer S, Viotti C, Robinson DG. An improved procedure for low-temperature embedding of High Pressure frozen and freeze-substituted plant tissues resulting in excellent structural preservation and contrast. J Microsc. 2012;247:43-47.

91. McDonald KL. Out with the old and in with the new: rapid specimen preparation procedures for electron microscopy of sectioned biological material. Protoplasma. 2014;251:429-448.

92. McDonald KL, Webb RI. Freeze substitution in 3 hours or less. J Microsc. 2011;243:227-233.

93. Monaghan P, Perusinghe N, Müller M. High Pressure freezing for immunocytochemistry. J Microsc. 1998;192:248-258.

94. McDonald KL. Rapid embedding methods into Epoxy and LR White Resins for morphological and immunological analysis of cryofixed biological specimens. Microsc Microanal. 2014;20:152-163.

95. Keene DR, Tufa SF. High pressure freezing of the aortic media retains relationships of cells, collagen and elastin. Microsc Microanal. 2005;11(Suppl. 2):1184-1185.

96. Zenner HL, Collinson LM, Michaux G, Cutler DF. High Pressure freezing provides insights into Weibel-Palade body biogenesis. J Cell Sci. 2007;120:2117-2125.

97. Valentijn KM, Valentijn JA, Jansen KA, Koster AJ. A new look at Weibel-Palade body structure in endothelial cells using electron tomography. J Struct Biol. 2008;161:447-458.

98. Sawaguchi A, McDonald KL, Forte JG. High Pressure freezing of isolated gastric glands provides new insight into the 
fine structure and subcellular localization of $\mathrm{H}+/ \mathrm{K}+$-ATPase in gastric parietal cells. J Histochem Cytochem. 2004;52:77-86.

99. Young RD, Lawrence PA, Duance VC, Aigner T, Monaghan P. Immunolocalization of collagen types II and III in single fibrils of human articular cartilage. J Histochem Cytochem. 2000;48:423-432.

100. Mühlfeld C, Richter J. High Pressure freezing and freeze substitution of rat myocardium for immunogold labeling of connexin 43. Anat Rec A Discov Mol Cell Evol Biol. 2006;288:1059-1067.

101. Tomova C, Humbel BM, Geerts WJC, Entzeroth R, Holthuis JCM, Verkleij AJ. Membrane contact sites between apicoplast and ER in Toxoplasma gondii revealed by electron tomography. Traffic. 2009;10:1471-1480.

102. Brown E, Mantell J, Carter D, Tilly G, Verkade P. Studying intracellular transport using High Pressure freezing and Correlative Light Electron Microscopy. Semin Cell Dev Biol. 2009;20:910-919.

103. McDonald KL. A review of High Pressure freezing preparation techniques for correlative light and electron microscopy of the same cells and tissues. J Microsc. 2009;235:273-281.

104. Mironov AA, Beznoussenko GV. Correlative microscopy: a potent tool for the study of rare ocrc pressr unique cellular and tissue events. J Microsc. 2009;235:308-321.

105. Tokuyasu KT, Singer SJ. Improved procedures for immunoferritin labeling of ultrathin frozen sections. J Cell Biol. 1976;71:894-906.

106. Tokuyasu KT. A study of positive staining of ultrathin frozen sections. J Ultrastruct Res. 1978;63:287-307.

107. Slot JW, Geuze HJ. Cryo-sectioning and immunolabeling. Nat Protoc. 2007;2:2480-2491.

108. Slot JW, Geuze HJ. Sizing of protein A-colloidal gold probes for immunoelectron microscopy.J Cell Biol. 1981;90:533-536.

109. Herpers B, Xanthakis D, Rabouille C. ISH-IEM : a sensitive method to detect endogenous mRNAs at the ultrastructural level. Nat Protoc. 2010;5:678-687.

110. Griffiths G, Brands R, Burke B, Louvard D, Warren G. Viral membrane proteins acquire galactose in trans Golgi cisternae during intracellular transport. J Cell Biol. 1982;95:781-792.

111. Geuze HJ, Slot JW. Disproportional immunostaining patterns of two secretory proteins in guinea pig and rat exocrine pancreatic cells. An immunoferritin and fluorescence study. Eur J Cell Biol. 1980;21:93-100.

112. Liou W, Geuze HJ, Slot JW. Improving structural integrity of cryo-sections for immunogold labeling. Histochem Cell Biol. 1996;106:41-58.

113. Tokuyasu KT. Use of poly(vinylpyrrolidone) and poly(vinyl alcohol) for cryoultramicrotomy. Histochem J. 1989;21:163-171.

114. Humbel BM, Stierhof YD. Cryo - Sectioning according to Tokuyasu. In: Cavalier A, Spehner D, Humbel BM (eds.) Handbook of Cryo - Preparation Methods for Electron Microscopy. Boca Raton, Florida: CRC Press; 2009:467-498.

115. Griffith JM, Posthuma G. A reliable and convenient Method mo store ultrathin thawed cryo-sections prior to immunolabeling. J Histochem Cytochem. 2002;50:57-62.

116. Stierhof YD, van Donselaar EG, Schwarz H, Humbel BM. Cryo-fixation, freeze-substitution rehydration and Tokuyasu cryo-sectioning. In: Cavalier A, Sphener D, Humbel BM (eds.). Handbook of Cryo - Preparation Methods for Electron Microscopy. Boca Raton, Florida: CRC Press; 2009:343-366.

117. Ripper D, Schwarz H, Stierhof Y. Cryo-section immunolabelling of difficult to preserve specimens: advantages of cryofixation, freeze-substitution and rehydration. Biol Cell. 2008;100:109-123.
118. Stierhof YD, El Kasmi F. Strategies to improve the antigenicity, ultrastructure preservation and visibility of trafficking compartments in Arabidopsis tissue. Eur J Cell Biol. 2010;89:285-297.

119. Griffiths G, Simons K, Warren G, Tokuyasu KT. Immunoelectron microscopy using thin, frozen sections - application to studies of the intracellular transport of Semliki Forest virus spike glycoproteins. Methods Enzymol. 1983;96:466-485.

120. van Donselaar EG, Posthuma G, Zeuschner D, Humbel BM, Slot JW. Immunogold labeling of cryo-sections from High Pressure frozen cells. Traffic. 2007;8:471-485.

121. Griffith J, Mari M, De Mazie A, Reggiori F. A Cryo-sectioning procedure for the ultrastructural analysis and the immunogold labelling of yeast Saccharomyces cerevisiae. Traffic. 2008;9:1060-1072.

122. Griffith J, Pe alva MA, Reggiori F. Adaptation of the Tokuyasu method for the ultrastructural study and immunogold labelling of filamentous fungi. J Electron Microsc. (Tokyo). 2011;60:211-216.

123. Stradalova V, Gaplovska-Kysela K, Hozak P. Ultrastructural and nuclear antigen preservation after High Pressure freezing/freeze-substitution and low-temperature LR White embedding of HeLa cells. Histochem Cell Biol. 2008;130:1047-1052.

124. Sobol M, Philimonenko VV, Hozak P. Comparison of methods of High Pressure freezing and automated freeze -substitution of suspension cells combined with LR White embedding. Histochem Cell Biol. 2010;134:631-641.

125. D'Amico F, Skarmoutsou E. Quantifying immunogold labelling in transmission electron microscopy. J Microsc. 2008;230:9-15.

126. Triffo WJ, Palsdottir H, McDonald KL et al. Controlled microaspiration for High Pressure freezing: a new method for ultrastructural preservation of fragile and sparse tissues for TEM and electron tomography. J Microsc. 2009;230:278-287.

127. Ewald AJ, Huebner RJ, Palsdottir H et al. Mammary collective cell migration involves transient loss of epithelial features and individual cell migration within the epithelium.J Cell Sci. 2012;125:2638-2654.

128. Venter C, van der Merwe CF, Oberholzer HM, Bester MJ, Taute H. Feasibility of high pressure freezing with freeze substitution after long-term storage in chemical fixatives. Microsc Res Tech. 2013;76:942-946.

129. Sabanay I, Arad T, Weiner S, Geiger B. Study of vitrified, unstained frozen tissue sections by cryoimmunoelectron microscopy. J Cell Sci. 1991;100:227-236.

130. Bokstad M, Sabanay H, Dahan I, Geiger B, Medalia O. Reconstructing adhesion structures in tissues by cryo-electron tomography of vitrified frozen sections. J Struct Biol. 2012;178:76-83.

131. Karreman MA, van Donselaar EG, Gerritsen HC, Verrips CT, Verkleij AJ. VIS2FIX: a high-speed fixation method for immuno-electron microscopy. Traffic. 2011;12:806-814.

132. Karreman MA, Agronskaia AV, Verkleij AJ, Cremers FF, Gerritsen HC, Humbel BM. Discovery of a new RNAcontaining nuclear structure in UVC-induced apoptotic cells by integrated laser electron microscopy. Biol Cell. 2009;101:287-299.

133. Jahn KA, Barton DA, Kobayashi K, Ratinac KR, Overall RL, Braet F. Correlative microscopy: providing new understanding in the biomedical and plant sciences. Micron. 2012;43:565-582.

134. Karreman MA, Agronskaia AV, van Donselaar EG et al. Optimizing immuno-labeling for correlative fluorescence 
and electron microscopy on a single specimen. J Struct Biol. 2012;180:382-386.

135. Hsieh C, Leith A, Mannella CA, Frank J, Marko M. Towards high-resolution three-dimensional imaging of native mammalian tissue: electron tomography of frozen-hydrated rat liver sections. J Struct Biol. 2006;153:1-13.

136. Lucas MS, Günthert M, Gasser P, Lucas F, Wepf R. Bridging microscopes: 3D correlative light and scanning electron microscopy of complex biological structures. Methods Cell Biol. 2012;111:325-356.
137. Faas FG, Bárcena M, Agronskaia AV et al. Localization of fluorescently labeled structures in frozen-hydrated samples using integrated light electron microscopy. J Struct Biol. 2013;181:283-290.

138. Popescu LM, Faussone-Pellegrini M-S. TELOCYTES a case of serendipity: the winding way from Interstitial Cells of Cajal (ICC), via Interstitial Cajal-Like Cells (ICLC) to TELOCYTES. J Cell Mol Med. 2010;14:729-740.

139. Zheng Y, Bai C, Wang X. Telocyte morphologies and potential roles in diseases. J Cell Physiol. 2012;227:2311-2317.

Submitted: 6 February, 2014 Accepted after reviews: 7 April, 2014 